Int. J. Morphol.,

36(1):92-96, 2018.

\title{
Predictors of Shoulder Degeneration in the KwaZulu-Natal Population of South Africa
}

\author{
Indicadores de la Degeneración del Hombro en la Poblacion KwaZulu/Natal de Sudáfrica
}

\author{
N. Naidoo'; L. Lazarus²; A. Van Tongel ${ }^{3}$; S. A. Osman ${ }^{4}$ \& K. S. Satyapal ${ }^{2}$
}

NAIDOO, N.;LAZARUS, L.; VAN TONGEL, A.; OSMAN, S. A. \& SATYAPAL, K. S. Predictors of shoulder degeneration in the KwaZulu-Natal population of South Africa. Int. J. Morphol., 36(1):92-96, 2018.

SUMMARY: The critical shoulder angle and acromion index are conventional radiological tools employed as predictors of shoulder degeneration. As they represent the static components of glenohumeral stability, the scapulo-humeral geometry and underlying subacromial tissue appear as the resultant cause-effect factors. Consequently, the purpose of this study was to investigate the critical shoulder angle and acromion index as interrelated parameters within the South African population. The measurement of both biomechanical parameters was conducted on two-hundred and sixty $(\mathrm{n}=260)$ true AP radiographs. This was a cross-sectional study that also incorporated the demographic representation of the population group which was analysed accordingly. The mean values recorded for both the critical shoulder angle $\left(36.31 \pm 5.84^{\circ}\right)$ and acromion index $(0.74 \pm 0.13)$ suggested rotator cuff arthropathy. The results confirmed the theories of Nyffeler et al. (2006) and Moor et al. (2012) who alluded to glenoid inclination and the acromial coverage over the humeral head. A significant proportionality correlation, verified by a $\mathrm{P}$ value of 0.000 , was established between the acromion index and critical shoulder angle which may assist to differentiate between normal asymptomatic shoulders and those with cuff disease. Furthermore, these predictors of shoulder degeneration may present as a preventative tool against tear progression.

KEY WORDS: Critical shoulder angle; Acromion index; Predictors of shoulder degeneration; Rotator cuff tendinopathy; Subacromial disease.

\section{INTRODUCTION}

Since the critical shoulder angle and acromion index are considered to be characteristic of subacromial pathology, there is much need for the evaluation of these biomechanical parameters as separate and interrelated predictors of shoulder degeneration in the South African population (Armfield $e t$ al., 2003; Moor et al., 2013; Bouaicha et al., 2014; Gerber et al., 2014; Spiegl et al., 2016). As the scapulo-humeral geometry related to these parameters present as static stabilisers, the relationship between the latter and the surrounding musculature determines the stability of the shoulder (Armfield et al.; Moor et al., 2013; Gerber et al.).

The critical shoulder angle, an analytical tool of an individual's scapular anatomy, quantifies the angle between the superior and inferior osseous glenoidal margins and the lateral-most aspect of the acromion (Moor et al., 2012; Bouaicha et al.; Gerber et al.; Daggett et al., 2015; Spiegl et al.; Viehöfer et al., 2016). This novel radiological parameter provides reasoning for the occurence of glenohumeral osteoarthritis or rotator cuff tears by measuring both the la- teral acromial extension and the glenoid slope (Moor et al., 2013; Gerber et al.; Spiegl et al.). As a result, Moor et al. (2012) reported a critical shoulder angle of less than $30^{\circ}$ to depict glenohumeral osteoarthritis, while that greater than $35^{\circ}$ was reflective of degenerative rotator cuff tears. Furthermore, the acromial coverage provided by the variable acromial length has been theorised to increase or decrease the size of the deltoid moment arm, thus causing a decentralization of the deltoid force vector on the rotational centre of glenoid fossa (Moor et al., 2014a; Viehöfer et al.).

Similarly, Nyffeler et al. (2006) proposed the model of the acromion index, which defines the relation between the lateral extensions of the acromion and the humeral head from the glenoid fossa. Since the force vector commences at the lateral acromial extension, it is closely associated with the deltoid insertion site, thus resulting in the superior displacement of the humeral head such that the subacromial complex is impinged (Hanciau et al., 2012; Miyazaki et al., 2015). Consequently, a higher acromion index is indicative of

\footnotetext{
${ }^{1}$ College of Medicine, Mohammed Bin Rashid University of Medicine and Health Sciences, Dubai Healthcare City, United Arab Emirates.

${ }^{1}$ Department of Clinical Anatomy, School of Laboratory Medicine and Medical Sciences, University of KwaZulu-Natal, Westville Campus, Durban, South Africa.

${ }^{2}$ Department of Physical Medicine and Orthopaedic Surgery, Ghent University, Ghent, Belgium.

${ }^{3}$ Orthopaedics, Suite 11 Medical Centre East, Life Entabeni Hospital, Durban, South Africa.
} 
a larger lateral acromial extension that may increase the probability of subacromial pathology (Hanciau et al.).

Although many international reports exist, no known South African study has investigated nor incorporated both of the abovementioned parameters.

Hence, the aim of this study was to determine the critical shoulder angle and acromion index within the KwaZulu-Natal population of South Africa.

\section{MATERIAL AND METHOD}

Two-hundred and sixty $(\mathrm{n}=260)$ randomly-selected true anteroposterior radiographs of shoulder patients were extracted from the database of Life Entabeni Hospital, Durban, KwaZulu-Natal, South Africa, in accordance with hospital protocol. This study employed a cross-sectional approach in which patient history and/or pathology were unknown. The GE Healthcare Centricity PACS - IW Dynamic Imaging (3.7.3.9) was used to measure the respective parameters.

The critical shoulder angle was measured as the angle between the line joining the superior and inferior glenoidal margins and the line connecting the inferior glenoidal margin to the lateral-most aspect of the acromion (Fig. 1).

The acromion index presented as a ratio of two calculated distances, i.e. A) Distance from glenoid plane to the lateral-most point of the acromion, and B) Distance from the glenoid plane to the lateralmost aspect of the humeral head (Fig. 2).

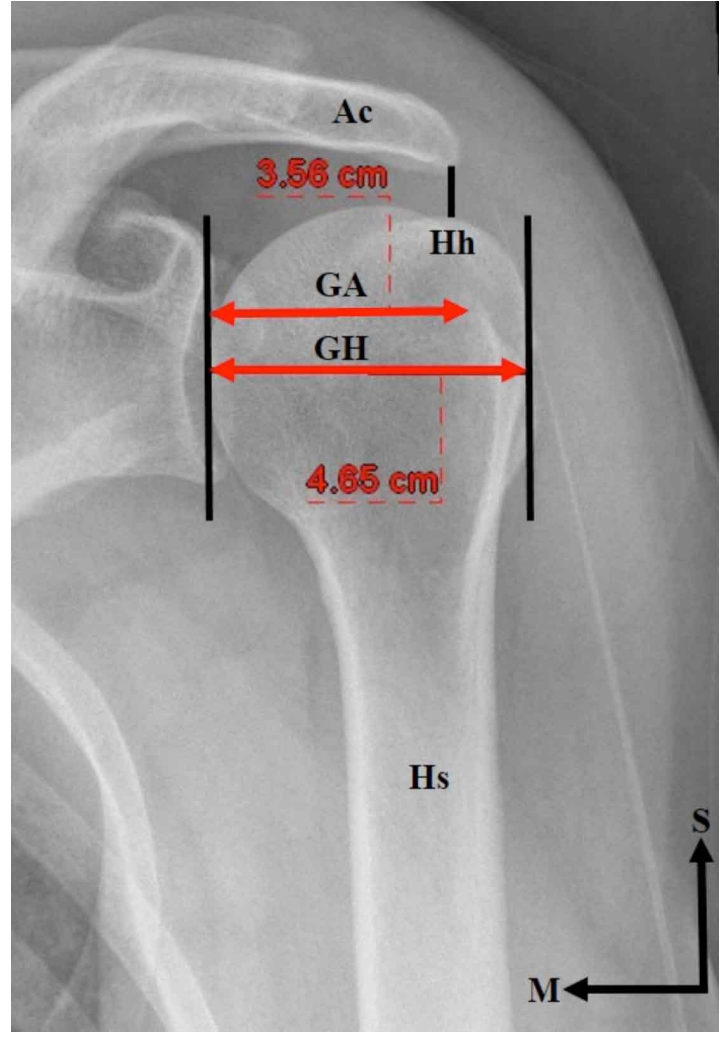

Fig. 2. Acromion index as stated by Nyffeler et al. (2006) (AP view of left shoulder). Key: Ac: Acromion; CSA: Critical shoulder angle; GA: Distance from glenoid plane to the lateral-most point of the acromion GH - Distance from the glenoid plane to the lateral-most aspect of the humeral head Hh - Humeral head; Hs - Humeral shaft; M - Medial; S - Superior.
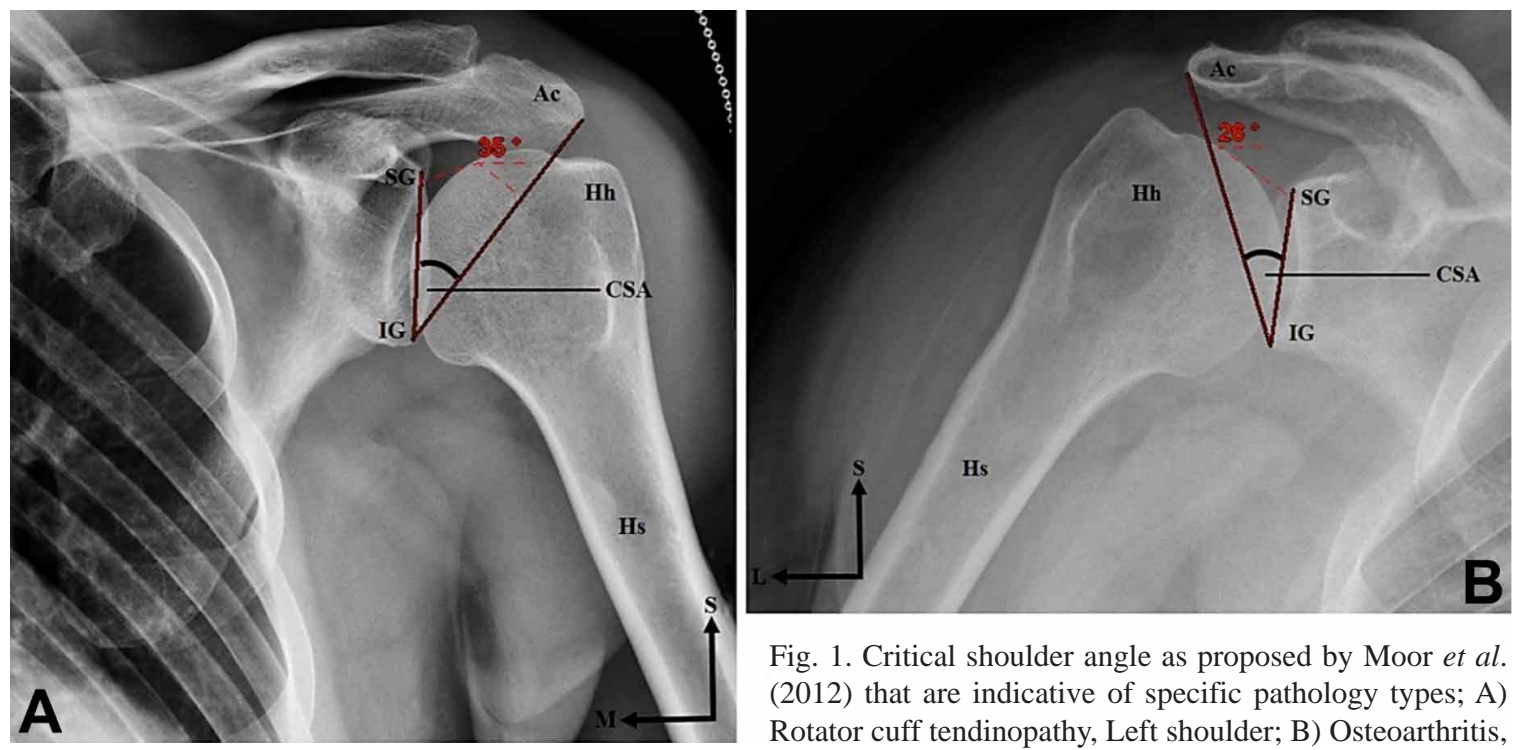

Fig. 1. Critical shoulder angle as proposed by Moor et al. (2012) that are indicative of specific pathology types; A) Rotator cuff tendinopathy, Left shoulder; B) Osteoarthritis, Right shoulder (AP view) Key:Ac: Acromion; CSA: Critical shoulder angle; Hh: Humeral head; Hs: Humeral shaft; IG: Inferior glenoidal margin; L: Lateral; M: Medial; S: Superior; SG: Superior glenoidal margin 
Based upon a $95 \%$ confidence interval, the IBM Statistical Package for Social Sciences (SPSS) version 21.0 was used to analyze the data collected. Comparisons between the predictors of shoulder degeneration, race (Black: 3, Coloured: 25, Indian: 41, White: 191), sex (Male: 144, Female: 116), side (Left: 124, Right: 136) and age $(53.56 \pm 15.04$ years old) were also performed. $P$ values of less than 0.05 were noted to be statistically significant.

\section{RESULTS}

The standard mean critical shoulder angle and acromion index were calculated to be $36.31 \pm 5.84^{\circ}$ and $0.74 \pm 0.13$, respectively (Table I).

Male individuals presented with a mean critical shoulder angle of $35.60 \pm 5.73^{\circ}$, while female individuals had a mean angle of $37.18 \pm 5.89^{\circ}$ (Table I). Moreover, a statistically significant $\mathrm{P}$ value of 0.031 was yielded for the mean critical shoulder angle between males and females (Table I).

The mean critical shoulder angles on the left and right sides were $36.09 \pm 6.53^{\circ}$ and $36.51 \pm 5.16^{\circ}$, respectively (Table I).

With regard to the four race groups, the mean critical shoulder angles were as follows: Black $\left(39.78 \pm 3.87^{\circ}\right)$, Coloured $\left(36.36 \pm 7.64^{\circ}\right)$, Indian $\left(36.80 \pm 4.87^{\circ}\right)$ and White $\left(36.09 \pm 5.80^{\circ}\right)$ (Table I).
The mean acromion index in males and females was found to be $0.71 \pm 0.11$ and $0.77 \pm 0.16$, respectively (Table I). In addition, a $P$ value of statistical significance $(0.001)$ was recorded for the comparison of the mean acromion index between male and female individuals (Table I). The left side presented with a mean acromion index of $0.76 \pm 0.15$, while that of the right appeared to be $0.72 \pm 0.12$ (Table I). This comparison between left and right sides was accompanied by a statistically significant P value of 0.007 (Table I). Although the Black race group was found to have a mean acromion index of $0.73 \pm 0.59$, the Coloured, Indian and White race groups yielded indices of $0.74 \pm 0.14,0.75 \pm 0.16$ and $0.73 \pm 0.14$, respectively (Table I).

A statistically significant $P$ value of 0.000 was recorded for the correlation between the mean critical shoulder angle and the mean acromion index (Table I).

\section{DISCUSSION}

Despite the lack of longitudinal studies, many reports have considered the variable scapulo-humeral geometry to be indicative of specific pathology types (Moor et al., 2012; Moor et al., 2014b; Gerber et al.; Spiegl et al.). Consequently, there is speculation as to whether changes in the bone geometry exhibit a cause-effect relationship (Moor et al., 2014b; Spiegl et al.).

This study investigated the critical shoulder angle and acromion index as interrelated parameters and accounted for

Table I. Mean values of the predictors of shoulder degeneration.

\begin{tabular}{|c|c|c|c|}
\hline \multicolumn{2}{|c|}{ P arameter } & \multirow{2}{*}{$\begin{array}{c}\begin{array}{c}\text { Mean Critical } \\
\text { Shoulder Angle } \\
\text { (degrees } 0)\end{array} \\
36.31 \pm 5.84\end{array}$} & \multirow{2}{*}{$\begin{array}{l}\text { Mean Acromion } \\
\text { Index } \\
0.74 \pm 0.13\end{array}$} \\
\hline $\mathrm{S} \tan$ & & & \\
\hline \multirow{2}{*}{ Sex } & Male & $35.60 \pm 5.73$ & $0.71 \pm 0.11$ \\
\hline & Female & $37.18 \pm 5.89$ & $0.77 \pm 0.16$ \\
\hline \multicolumn{2}{|c|}{$P$ Value } & $0.031 *$ & $0.001 *$ \\
\hline \multirow{2}{*}{ Side } & Left & $36.09 \pm 6.53$ & $0.76 \pm 0.15$ \\
\hline & Right & $36.51 \pm 5.16$ & $0.72 \pm 0.12$ \\
\hline \multicolumn{2}{|c|}{$P$ Value } & 0.565 & $0.007 *$ \\
\hline \multirow{4}{*}{ Race } & Black & $39.78 \pm 3.87$ & $0.73 \pm 0.59$ \\
\hline & Coloured & $36.36 \pm 7.64$ & $0.74 \pm 0.14$ \\
\hline & Indian & $36.80 \pm 4.87$ & $0.75 \pm 0.16$ \\
\hline & White & $36.09 \pm 5.80$ & $0.73 \pm 0.14$ \\
\hline \multicolumn{2}{|c|}{$P$ Value } & 0.174 & 0.892 \\
\hline \multicolumn{2}{|c|}{ Age $P$ Value } & 0.119 & 0.196 \\
\hline \multicolumn{2}{|c|}{ Critical Shoulder Angle $P$ Value } & - & $0.000 *$ \\
\hline \multicolumn{2}{|c|}{ Acromion Index $P$ Value } & $0.000 *$ & - \\
\hline
\end{tabular}

Key: * - Significant P Value. 
the demographic representation of the KwaZulu-Natal population, thus providing a unique South African perspective. Although the earlier report of Hamid et al. (2012) detailed the acromion index within a Johannesburg population, the racial distribution of the sample was not considered.

In addition to the standard mean critical shoulder angle, those recorded for gender, side and race were all greater than $35^{\circ}$. While the quality of the cuff was not described in this study, the mean angular values may suggest the presence of rotator cuff tears, therefore corroborating the findings of Moor et al. (2012).

This study adopted the mean values of the acromion index classification scheme that was proposed by Nyffeler et al. viz. i) rotator cuff tears: $0.73 \pm 0.06$; ii) glenohumeral osteoarthritis: $0.60 \pm 0.08$; iii) normal shoulders: $0.64 \pm 0.06$. Similarly, the mean acromion index for the standard, sex, side and race were all found to be greater than 0.71 , thus agreeing with the model of Nyffeler et al. Although, a high acromion index is linked to rotator cuff tears, $\mathrm{Gu} \& \mathrm{Yu}(2013)$ found no association between a low acromion index and glenohumeral osteoarthritis.

Subsequently, in accordance with the theories of Nyffeler et al. and Moor et al. (2012), all mean values documented for the critical shoulder angle and the acromion index suggested the presence of degenerative rotator cuff tears. Since these parameters were characterized by long acromia with superiorly-inclined glenoid fossae, it was understood that the smaller deltoid moment arm may result in the decentralization of the force vector on the glenoid fossa (Moor et al., 2014a; Viehöfer et al.). Therefore, a greater load would be required by the rotator cuff muscles to counterbalance the deltoid force, thus initiating rotator cuff tears (Moor et al., 2013; Moor et al., 2014a; Bouaicha et al.; Daggett et al.; Spiegl et al.).

Interestingly, female individuals presented with larger mean critical shoulder angles and acromial indices than male individuals which were substantiated by statistically significant $\mathrm{P}$ values. This differed from the study of Robinette et al. (1979), who reported that body proportionality differed between males and females by associating the smaller dimensional values of the female to primary sex characteristics. Although the mean critical shoulder angle was somewhat greater on the right side, the mean acromion index was larger on the left side. This difference in the dominance of side regarding both predictors of shoulder degeneration was further validated by a statistically significant $P$ value of 0.007 . While the differences in the mean critical shoulder angle and acromion index were minor among the race groups, the former and latter were slightly increased in the Black and Indian groups, respectively. These minor differences may be due to the biotype specific to each race group (Miyazaki et al.).

In this study, the absence of a statistically significant difference for the comparison of age with the critical shoulder angle $(\mathrm{P}$ value $=0.119)$ differed from the age-related conjecture of Moor et al. (2014a). However, the statistically significant $P$ value of 0.000 confirmed a statistically significant correlation between the critical shoulder angle and the acromion index.

It may be recommended that the acromial morphology, mass of the scapula and humerus, and the joint reaction forces be considered for future studies as this may clarify the extent to which the altered scapulo-humeral anatomy influences the critical shoulder angle and the acromion index. Since the documentation of complete patient records is not optimal in South Africa, this study was based on a cross-sectional approach. Therefore, it may be suggested to place future emphasis on a longitudinal study that incorporates both, cuff quality and patient history and/or pathology.

CONCLUSION: In this study, shoulder patients in South Africa presented with relatively increased critical shoulder angles and acromial indices.

NAIDOO, N.;LAZARUS, L.; VAN TONGEL, A.; OSMAN, S. A. \& SATYAPAL, K. S. Indicadores de la degeneración del hombro en la población KwaZulu/Natal de Sudáfrica. Int. J. Morphol., 36(1):92-96, 2018.

RESUMEN: El ángulo crítico del hombro y el índice acromial son herramientas radiológicas convencionales empleadas como indicadores de la degeneración del hombro. Debido a que representan los componentes estáticos de la estabilidad glenohumeral, la geometría escápulo-humeral y el tejido subacromial subyacente aparecen como los factores causa-efecto resultantes. En consecuencia, el propósito de este estudio fue investigar el ángulo crítico del hombro y el índice acromial como parámetros interrelacionados dentro de la población sudafricana. La medición de ambos parámetros biomecánicos se realizó en 260 radiografías antero-posteriores (AP). Se realizó un estudio transversal que también incorporó la representación demográfica del grupo de la población que fue analizada. Los valores medios registrados tanto para el ángulo crítico del hombro $\left(36,31 \pm 5,84^{\circ}\right)$ como para el índice del acromión $(0,74 \pm 0,13)$ sugirieron una artropatía del manguito rotador. Los resultados confirmaron las teorías de Nyffeler et al. (2006) y Moor et al. (2012) que aludían a la inclinación glenoide y a la cobertura acromial sobre la cabeza humeral. Se estableció una correlación de proporcionalidad significativa, verificada por un valor de $\mathrm{P}$ de 0,000 , entre el índice acromial y el ángulo crítico del hombro, lo que puede ayudar a diferenciar entre los hombros asintomáticos normales y aquellos con enfermedad del manguito rotador. Además, estos predictores de degeneración del hombro pueden ser útiles como una herramienta preventiva contra la progresión del desgarro.

PALABRAS CLAVE: Angulo crítico del hombro; Índice acromial; Indicadores degeneración del hombro; Tendinopatía del manguito rotador; Síndrome subacromial. 


\section{REFERENCES}

Armfield, D. R.; Stickle, R. L.; Robertson, D. D.; Towers, J. D. \& Debski, R. E. Biomechanical basis of common shoulder problems. Semin. Musculoskelet. Radiol., 7(1):5-18, 2003.

Bouaicha, S.; Ehrmann, C.; Slankamenac, K.; Regan, W. D. \& Moor, B. K. Comparison of the critical shoulder angle in radiographs and computed tomography. Skeletal Radiol., 43(8):1053-6, 2014.

Daggett, M.; Werner, B.; Collin, P.; Gauci, M. O.; Chaoui, J. \& Walch, G. Correlation between glenoid inclination and critical shoulder angle: a radiographic and computed tomography study. J. Shoulder Elbow Surg., 24(12):1948-53, 2015.

Gerber, C.; Snedeker, J. G.; Baumgartner, D. \& Viehöfer, A. F. Supraspinatus tendon load during abduction is dependent on the size of the critical shoulder angle: A biomechanical analysis. J. Orthop. Res., 32(7):9527, 2014.

Gu, G. \& Yu, M. Y. Imaging features and clinical significance of the acromion morphological variations. J. Nov. Physiother, S2:003, 2013.

Hamid, N.; Omid, R.; Yamaguchi, K.; Steger-May, K.; Stobbs, G. \& Keener, J. D. Relationship of radiographic acromial characteristics and rotator cuff disease: a prospective investigation of clinical, radiographic, and sonographic findings. J. Shoulder Elbow Surg., 21(10):1289-98, 2012.

Hanciau, F. A.; da Silva, M. A.; Martins, F. S. \& Ogliari, A. Association clinical-radiographic of the acromion índex and the lateral acromion angle. Rev. Bras. Ortop., 47(6):730-5, 2012.

Miyazaki, A. N.; Fregoneze, M.; Santos, P. D.; Da Silva, L. A.; Menegassi Martel, É.; Debom, L. G.; Andrade, M. L. \& Checchia, S. L. Radiographic study on the acromion index and its relationship with rotator cuff tears. Rev. Bras. Ortop., 45(2):151-4, 2015.

Moor, B. K.; Bouaicha, S.; Rothenfluh, D. A.; Sukthankar, A. \& Gerber, C. Is there an association between the individual anatomy of the scapula and the development of rotator cuff tears or osteoarthritis of the glenohumeral joint?: A radiological study of the critical shoulder angle. Bone Joint J., 95-B(7):935-41, 2013.

Moor, B. K.; Röthlisberger, M.; Müller, D. A.; Zumstein, M. A.; Bouaicha, S.; Ehlinger, M. \& Gerber, C. Age, trauma and the critical shoulder angle accurately predict supraspinatus tendon tears. Orthop. Traumatol. Surg. Res., 100(5):489-94, 2014a.

Moor, B. K.; Wieser, K.; Slankamenac, K.; Gerber, C. \& Bouaicha, S. Relationship of individual scapular anatomy and degenerative rotator cuff tears. J. Shoulder Elbow Surg., 23(4):536-41, 2014b.

Moor, B.; Bouaicha, S.; Rothenfluh, D. A.; Sukthankar, A. \& Gerber, C. The critical shoulder angle: A new radiological tool in the assessment of patients with degenerative shoulder pathologies. Orthop. Traumatol. (Basel), 96:1, 2012.

Nyffeler, R. W.; Werner, C. M.; Sukthankar, A.; Schind, M. R. \& Gerber, C. Association of a large lateral extension of the acromion with rotator cuff tears. J. Bone Joint Surg. Am., 88(4):800-5, 2006.

Robinette, K.; Churchill, T. \& McConville, J. T. A Comparison of Male and Female Body Sizes and Proportions. Yellow Springs, Anthropology Research Project, 1979.

Spiegl, U. J.; Horan, M. P.; Smith, S. W.; Ho, C. P. \& Millett, P. J. The critical shoulder angle is associated with rotator cuff tears and shoulder osteoarthritis and is better assessed with radiographs over MRI. Knee Surg. Sports Traumatol. Arthrosc., 24(7):2244-51, 2016.

Viehöfer, A. F.; Snedeker, J. G.; Baumgartner, D. \& Gerber, C. Glenohumeral joint reaction forces increase with critical shoulder angles representative of osteoarthritis-A biomechanical analysis. J. Orthop. Res., 34(6):1047$52,2016$.

\author{
Corresponding author: \\ Prof. K.S. Satyapal \\ Clinical Anatomy \\ School of Laboratory Medicine and Medical Sciences \\ College of Health Sciences \\ University of KwaZulu-Natal \\ Private Bag X54001 \\ Durban \\ 4000 \\ SOUTH AFRICA
}

E-mail address: satyapalk@ukzn.ac.za

Received: 05-10-2016

Accepted: 21-09-2017 